\title{
EDUCAÇÃO E INFÂNCIA: alguns apontamentos sobre o brincar das crianças
}

\section{EDUCATION AND CHILDHOOD: Some notes about the children's play}

\author{
Rogério Rodrigues \\ Universidade Federal de Itajubá (UNIFEI)
}

\section{RESUMO}

O presente trabalho tem por objetivo analisar o lugar do brincar das crianças na infância numa proposição crítica, tendo como referência a Psicanálise na Educação. O método utilizado tem como proposição investigativa o campo da teoria crítica no sentido de evidenciar o que é estranho no modo comum do brincar das crianças. Para tanto, serão reproduzidas e analisadas três pequenas cenas do cotidiano que se apresentam nas interações entre o educar e o brincar. As principais conclusões desse estudo indicam que, na modernidade, ocorre a precarização do brincar tanto no espaço urbano como no espaço escolar em subordinar o sujeito como objeto, principalmente, por destituir as condições criativas. Conclui-se que, no campo da gestão pública, mais propriamente, no setor do campo educacional, as novas configurações do brincar alteram a singularidade do sujeito e que, no plural do social, reduz-se em sujeitos alheios à própria cultura e destituídos de pensamento no sentido de elaborar a crítica.

Palavras-chave: Educação; Psicanálise na Educação; Infância; Educação Infantil; Brincar.

\section{ABSTRACT}

The current paper has like objective analyze the place of the children's play at childhood in a critical proposition, having as reference the Education's Psychoanalysis. The method used has as investigative proposition the critical theory field at the direction of highlight what is strange at the common mode of children's play. For this, it will be reproduced and analyzed three small daily scenes that present at the interactions between teach and play. The main conclusions about this study indicates that, in modern times, occur the play failing as at the city space as at the school space in subordinate the person as object, mainly, because dismiss the creative conditions. In conclusion, at the public management field, more properly, at the educational field sector, the new settings of playing change the person singularity and that, at the plural, reduce itself in unrelated people to their own culture and dismissed of thinking for elaborate the critic.

Keywords: Education; Education's Psychoanalysis; Childhood; Children's Education; Play. 
Podemos ir a algumas lojas e encontrarmos roupas de crianças, brinquedos de crianças, livros para crianças, objetos para os quartos das crianças. Podemos repassar o programa de espetáculo e veremos filmes para crianças, teatro para crianças, música para crianças, exposições para crianças, parques infantis, circos, festas infantis, programas de televisão para crianças (LARROSA, 2004, p. 183).

\section{Introdução - As vicissitudes do brincar em tempos de modernidade}

Toda vez que observo alguém "brincando com o celular" produz-se a sensação de estranhamento, pois esse brincar evidencia uma relação de subordinação do sujeito com a máquina na constituição de novas formas de ludicidade. Portanto, de modo geral, se observar, no cotidiano social, que vivemos numa época de outras formas do brincar, numa transição de um passado recente, em que éramos os sujeitos da ação, para os tempos atuais, em que somos apêndices dos equipamentos tecnológicos. ${ }^{1}$

Esse reposicionamento do sujeito no brincar produz também o mal estar de que algo não vai muito bem no brincar, pois os olhos desses sujeitos fecham-se nessa estreita janela chamada tela do celular para enxergar o mundo por outros olhos ou naquilo que paradoxalmente denomina-se como "realidade virtual". Essa mania do brincar com o celular é algo que também atinge a fase adulta, pois na realização de mega show da banda dos Rolling Stones, o seu componente, Mick Jagger, disse em entrevista que a "(...) capital paulista é a cidade do celular e parece que as pessoas em SP assistem ao show pelo celular" (REDAÇÃO, 2017). Apesar desse algo estranho, que é perceptível no modo de usar o equipamento, no caso do brincar da criança, o senso comum ainda insiste em responder a essa situação com as seguintes palavras: "Deixe-a ficar brincando com celular! Assim ela se distrai!". A partir desse algo comum que se responde sobre o brincar com o celular a nossa pergunta central nesse texto seria responder qual seria o lugar do brincar no processo formativo do sujeito?

\footnotetext{
${ }^{1}$ Parte desse trabalho inspira-se no dossiê intitulado "Ludicidade, Conhecimento e Corpo" que organizamos e foi publicado em 2018 na Revista em Aberto (REIS \& RODRIGUES, 2018).
} 
Desse modo, a partir dessa primeira aproximação sobre a questão do brincar, o que se pode constatar é que existem vários elementos nesse ato que no cenário das cidades são compartilhados entre pais e educadores como algo comum e corriqueiro. Entretanto, a nossa posição sobre esse assunto torna-se contrária a isso, compreendemos que isso seja a ponta de icerberg nas vicissitudes do brincar, que podem indicar as transformações subjetivas numa sociedade que se constitui na solidão dos sujeitos no meio das multidões. Esse estado de solidão condiz-se à sociedade em que o tecido social rompe-se e perde-se a condição de compaixão e solidariedade e que resulta naquilo que Freud denominou com “(...) o nome de 'narcisismo das pequenas diferenças'” (FREUD, 1990a, p. 119).

Vivemos numa sociedade em que buscamos o ideal de inclusão da diferença, numa concepção de igualdade que constitui as diferenças em diversos grupos e semigrupos numa razão de divisão com tendência ao infinito, pois sempre é possível encontrar algum tipo de diferença que ainda não foi inclusa no social. Entretanto, como essa condição moderna do sujeito pautado no narcisismo tem afetado o modo de brincar das crianças?

Para respondermos a esse questionamento, partimos da suposição contrária ao senso comum, de que o modo de brincar das crianças não é algo tão comum e natural, pois se constituem como elementos no campo da cultura cuja inserção e função “(...) se assemelha a uma das seções de um mundo moldado como uma gigantesca loja de departamento em que vivem, acima de tudo, pessoas transformadas em consumidores" (BAUMAN, 2013, p. 20). Desse modo, poder escrever e, principalmente, pensar sobre o brincar constitui-se na possibilidade de representar certo incômodo em toda vez que vou comprar um brinquedo para minha filha, pois o sentimento que prevalece é: consuma e seja feliz.

Fico perguntando: em qual lugar estaria o brincar que rompe com essa lógica do consumo? Podemos observar que atualmente esse brincar pautado no consumo constitui uma regressão no campo da cultura, pois grande parte do brincar das crianças transformou-se na perda dos elementos criativos. 
O brincar criativo fica comprometido em decorrência de que as cidades diminuíram os espaços de circulação, na redução das casas com quintais e no fechamento das praças com cercas e grades. A anulação desses espaços significa a perda da experiência como o lugar em que se poderia inventar algo diferente no uso do tempo livre, principalmente, para se criar algo na atividade. As praças públicas deixaram de ser públicas, pois as poucas que existem foram reduzidas em pequenos espaços e, em grande parte, cercadas, o que dificulta seu acesso. Nesse quadro estabelecido o brincar, para alguns poucos, ficou restrito a condomínios fechados e para outros, a grande maioria, às ruas violentas em meio ao trânsito de automóveis.

Outra esfera do brincar que também se encontra em transformação foi o deslocamento do mesmo para o interior da unidade escolar, em que o brincar tornou-se conteúdo pedagógico. O brincar como conteúdo pedagógico e escolar é a designação da rotina do fazer coisas somente com conteúdo e aprendizagem. Sem essa propriedade do brincar que seja pedagógico e, principalmente, que possa implicar o sujeito no modo de fazer coisas no campo da cultura escolar, o brincar não se justifica no interior da escola. Portanto, apesar dessa simples constatação na falta do lugar do brincar na infância que, de um lado, não tem espaço e, por outro lado, encontra-se sobrecarregado de significado, a tarefa seria analisar os efeitos dessas alterações, que não se apresentam como algo tão simples em sua demanda. Isso significa dizer que se torna preciso compreender toda a complexidade presente para resignificar o brincar nas cidades e nas escolas.

Compreende-se que analisar brincar como algo corriqueiro seja, em parte, o material comum que se perde no absurdo de se acreditar que as coisas são desse modo e assim devem ficar. Portanto, avalia-se que na Educação torna-se presente como elemento da função analítica em deixar transparecer aquilo que é comum, o estranho. Para Freud (1996b), o "estranhamento" é algo que pode ser reduzido ao “(...) retorno de coisas antigamente familiares que agora se encontram reprimidas". (FREUD, 1996b. p. 2500). Para evidenciar isso que é estranho no comum, serão reproduzidas três cenas que provocaram certo incômodo sobre a questão do brincar e que podem colaborar para interpretarmos esse movimento de 
transformação que se encontra presente nas cidades, educação e infância. Desse modo, na expressão discursiva do desejo da criança em "será que você pode brincar comigo?” passa ser interpretado numa demanda que se encontra numa estrutura da interface dos sujeitos entre si e com os espaços disponíveis nas cidades, pautados numa cultura do consumo, em que sua função

(...) não é satisfazer necessidades existentes, mas criar outras - ao mesmo tempo que mantém as necessidades já entranhadas ou permanentemente irrealizadas. Sua principal preocupação é evitar o sentimento de satisfação em seus antigos objetos e encargos, agora transformados em clientes; e, de maneira bem particular, neutralizar sua satisfação total, completa e definitiva, o que não deixaria espaço para outras necessidades e fantasias novas, ainda inalcançadas (BAUMAN, 2013, p. 21).

Já o modo de brincar desses sujeitos que se tornam "clientes" na unidade escolar reproduz o comportamento aceitável em torno da subjetividade daquele que incorpora em aprender o conteúdo pedagógico. Entre um lugar e outro, onde estaria o brincar na infância, que possa fazer o sujeito estar presente na tarefa de criar na atividade um tipo de pensamento, em ruptura com a cultura do consumo? Sabemos que, em parte, a resposta a esse questionamento trata-se de compreender que

(...) as crianças deixam de brincar em nome de uma tradição, de um savoir viure, isto é, em nome de um saber paterno ou fálico sempre parcial e passam a fazê-lo em nome de saberes psicológicos, ou seja, de uma certeza científica ou saber total sobre a lógica que por sua vez, supõe-se operando no real (LAJONQUIÈRE, 1992, p. 38).

Isso supõe que o brincar deveria ser levado a sério por parte dos adultos que se nomeiam como intelectuais da infância, no sentido de revelarem que em suas práticas instituídas deixam transparecer uma vontade de poder em querer controlar o outro em seu estado de desejo e que em nossa modernidade acaba resultando em torno de uma loja de brinquedo, encontrada em diversos Shoppings Center de nossas cidades, que já sabem de antemão que as crianças necessitam brincar, e, mais propriamente, consumir.

\section{Cena o1: o brincar das crianças nas cidades: as praças públicas como lugar de desencontro entre os sujeitos}


Fica em evidência que os diversos modos do brincar na infância encontramse contaminados com a concepção da sociedade do consumo, em que a aprendizagem é somente aquela que se possa traduzir como conteúdo pedagógico para a capacitação do sujeito. Na intenção de resistência a esse fenômeno social, constitui o hábito levar a minha filha, quase todos os dias, quando era um bebê, numa praça que ainda é pública, perto de casa. Ela nem conseguia andar direito e, nessa praça arborizada, havia um conjunto de acontecimentos. No caminho, ia narrando todas as coisas que encontrava pela frente, a começar pelos pássaros e arvores. Tinha a parada na casa do "lobo mau", que era bom, e batíamos à porta da casa dele: “Lobo mau! Você está em casa? Eu quero água!”. Após bebermos água, continuávamos em direção à praça, questionando se iríamos ou não encontrar outras crianças. Ela sempre desejava encontrar outras crianças nessa praça. Ficávamos na dúvida se na praça pública seria possível encontrar outras crianças, pois ela poderia estar cheia ou vazia de crianças.

Quando chegava à praça pública, já víamos de longe se havia crianças e estabelecemos o nosso conjunto de brincadeiras a percorrer: ficar na balança, cantando música; no gira-gira e na gangorra (sobe e desce). Depois, voltávamos para casa e, novamente, havia a parada na casa do "lobo mau/bom" para beber um pouco mais de água.

Em nossa interpretação, toda essa viagem de brincar de ir de casa para praça e da praça para casa apresentou-se como um brincar que se constituía numa verdadeira lição daquilo que vem antes e o que vem depois. Isso talvez pudesse constituir-se num preparativo para o seu ingresso na escola por outra perspectiva, e, no meu entender, essa viagem ainda continua nos dias de hoje, mas com a garantia que nessa praça chamada escola encontram-se outras crianças. Portanto, desde o início, as crianças deveriam ser preparadas para pensarem e falarem livremente nas praças. $\mathrm{O}$ que seria o brincar e o aprender na praça?

A lição é convocação em torno do texto: congregação de leitores. E assim, na lição, o texto converte-se em palavra emplazada, em palavra colocada na plaza, no lugar público, no lugar que ocupa o centro para simbolizar o que é de todos e não é de 
ninguém, o que é comum. E na plaza, enquanto palavra emplazada, o texto nos emplaza: pelo texto, cada um está emplazado no comum, emplazado pelo comum (LARROSA, 2004, p. 143).

Esse elemento comum vivenciado na praça permitia, à noite, principalmente, antes de dormir, elaborar esse momento, ao contar toda essa narrativa como uma história vivida do nosso dia. Essa narrativa dos nossos fazeres retratava as nossas brincadeiras de ir e vir da praça; no caso, era uma história de uma viagem para a lua, de foguete; quando chegávamos lá, brincávamos em todos os brinquedos, porque lá também havia a praça do brincar. O paradoxo dessa situação é que grande parte das escolas apostam na condição de evitar que as crianças devam ficar atentas e não façam pensamentos livres numa crítica em dizer que isso é distração ou ficar "viajando na lua".

Compreendemos que "viajar na lua" consiste num processo de imaginação e, principalmente, é a condição de pensar e projetar coisas. Esse imaginário é o elemento primordial para que talvez os denominados conteúdos escolares possam encontrar a força para impulsionar cada vez mais o pensamento da criança.

Quando comecei a levar minha filha à escola de educação infantil, estabelecemos um verdadeiro jogo de palavras para que ela entre dentro ou fora da escola. No seu universo imaginário, ela reconstitui o verdadeiro papel do educador como aquele que exerce função do "pedagogo", de encaminhar o sujeito para dentro do campo da cultura em que o brincar seria uma passagem do não saber para a constituição de novos saberes. Esse paralelo entre as praças públicas da cidade e a praça no interior dos muros da escola seria uma chave para se compreender como o sujeito está elaborando essa passagem para o campo da cultura, pois ela sempre afirma: "Vou esperar a professora para vir me buscar". No entanto, às vezes, ela me pergunta: "Por que devo ir para a escola?” Respondo, tragicamente, contaminado pela noção de mundo escolarizado, que é para encontrar outras crianças e aprender algo. Ela me diz novamente: "Mas eu quero somente brincar".

Fica novamente a questão: por qual motivo o brincar deve estar subjugado ao exercício pedagógico de levá-la para o campo da cultura? Nessa passagem de 
escolarização do mundo que se estabelece na entrada da escola, ela pede a presença da professora; apresento, a seguir, em detalhes, os seus motivos.

Por muitas vezes, ela não entrava na escola e queria ficar do lado de fora, ao meu lado, brincando comigo. Por algum tempo, isso foi feito: a professora vinha buscá-la, ela entrava chorando e perguntava: "Você vai estar me esperando?". Respondo: "Pode entrar, pois estarei esperando você". Ela entrava e ficava brincando no pátio à espera da professora ou da passagem entre o amor e o dever da escola, como lugar de ingresso no campo da cultura. Não seria isso a esperança de encontrar aquele que ama no lado de dentro da cultura e permitir ao sujeito que suporte permanecer e percorrer os diversos e dificultosos caminhos para acessar a cultura? Tudo indica que, nessa passagem para o campo da cultura, faça todo o sentido que "ensina-se por dever, aprende-se por amor" (LAJONQUIÈRE, 1992, p. 173).

Nesse tempo de espera e na presença da professora, fica a esperança de que algo ocorra nessa viagem, na praça chamada escola e que, minimamente, possa-se constituir a esperança de que ocorra um diálogo, em que

O professor - aquele que dá o texto a ler, aquele que dá o texto como um dom, nesse gesto de abrir o livro e de convocar à leitura - é o que remete o texto. O professor seleciona um texto para a lição e, ao abri-lo, o remete. Como um presente, como uma carta. Da mesma forma como aquele que remete um presente ou uma carta, o professor sempre está um pouco preocupado para saber se seu presente será aceito, se sua carta será bem recebida e merecerá alguma resposta (LARROSA, 2004, p. 140).

Neste caso, toda vez que vou buscá-la na escola, retomo a questão: "O que você fez hoje na escola?”. Ela me responde: “Eu não fiz nada! A professora não deixou brincar”. Respondo para ela: "Quando chegarmos em casa, vamos brincar!". Fica novamente outra esperança de que possamos, no amanhã, encontrar uma organização escolar que consiga compreender o brincar no educar das crianças, numa unidade em que esse desejo possa manifestar-se como a condição principal da inserção do sujeito no campo da cultura, no encontro com o outro.

Entretanto, nos dias atuais, a cidade em que moro possui uma restrição completa de espaço público para o brincar, pois praticamente não tem praça 
pública no município e o pouco espaço que existe encontra-se restrito o acesso em decorrência da violência urbana. O que temos como lugar coletivo estabelecido para o encontro publico dos sujeitos é o Shopping Center que, ironicamente, possui o nome de "Praça da Moça” que se refere a “(...) uma homenagem ao antigo Colégio das Freiras, hoje Centro de Memória, no qual estudavam exclusivamente meninas" (IBGE, 2017).

Atualmente, por vivermos numa cidade com reduzido número de praças públicas e sem memória, a nomeação do Shopping Center com o nome de praça torna possível interpretar dois lados de uma mesma moeda. De um lado, a significação que a praça pública deixou de existir como lugar de encontro entre os sujeitos com o outro e, por outro lado, a resignificação do lugar público como espaço privado e que se tornou o lugar restrito, organizado pelo comércio de coisas, mais propriamente, o desencontro dos sujeitos e a redução de seus encontros com os objetos mercadorias, que resulta na incorporação da cultura do Shopping Center no modo de viver em que o brincar nesses espaços fica reduzido ao preço que se pode pagar.

Podemos perguntar sobre como essa alteração dos espaços públicos afetou o brincar das crianças. Diria que, basicamente, as crianças perdem o lugar do convívio social como modo de compreender a viver na cidade ou, mais propriamente, existir no campo da cidadania. Não seria esse o motivo que a maioria dos planos de ensino escolar possui em seu objetivo "formar o cidadão"? Seria isso um modo de tentar reparar que não sabemos mais brincar, principalmente, ao se fazer a passagem da infância para o mundo adulto, quando se deixa de compreender os modos de viver nas cidades?

\section{Cena o2 - o brincar na escola como conteúdo pedagógico ou o saber ser professora}

Nesta situação de tentar resistir à concepção de aprender brincando como conteúdo pedagógico, estabeleci, como costume aos finais de semana, ir com a minha filha ao parque, na esperança de que ela possa encontrar outras crianças e, a 
partir desse encontro, fazer as suas diversas brincadeiras. Ficava apenas por perto para atender a alguma demanda de cuidar e, simultaneamente, não estou, para deixar que ela possa estar como sujeito. Desse modo, fiquei lidando comigo mesmo no caminho do educar em ter que escolher entre “(...) Sila da não-interferência e o Carídibis da frustração" (FREUD, 199ob, p. 147).

Na minha interpretação, o educar é lidar com o saber do "não saber" e que se apresenta em proferir a palavra de amor e, quando necessário, dizer que isso não pode! Sobre o dizer que isso não pode é que ocorreu algo que despertou a minha atenção.

Um menino de, aproximadamente, seis anos, que estava brincando com a minha filha, pegou um pouco de terra do chão e jogou no pé de uma moça adulta sentada num banco da praça. Essa adulta, ao sentir a terra entrando em contato com os seus pés, entrou em completo surto, resultado dessa ação e começou a gritar alto e a gesticular em tom de represália para o menino, dizendo: "Se fosse seu pai aqui, você jogaria terra no pé dele? Você jogaria? Jogaria?”. Essa moça virou para o meu lado e, com o olhar sábio e em voz mansa, disse para mim: "Eu já fui professora de criança e sei muito bem lidar com essa situação". Voltou-se novamente para a criança com o olhar fulminante e com palavras ríspidas disse: "Você nunca mais me faça uma coisa dessas!".

Aqui fica em evidência o estranhamento que se apresentou na falta de proporção, no grau de severidade, que consiste em inibir o outro por ter "jogado terra no pé”. O que se pode destacar para a discussão dessa cena é que esse adulto nada quer saber sobre o material que retorna do inconsciente no encontro com essa criança que, ao brincar em jogar terra naquele pé, coloca alguma coisa em questão.

O que percebi foi a existência do autoritarismo, nas entrelinhas, nos dizeres sussurrados desse adulto, que anunciava com as palavras "Eu já fui professora de criança e sei muito bem lidar com essa situação", que acreditava possuir propriedade de um saber sobre a infância e isso a "autorizava" a gritar com uma criança, que deixa transparecer "Uma imagem do totalitarismo: o rosto daqueles 
que, quando olham para uma criança, já sabem, de antemão, o que veem e o que têm de fazer com ela" (LARROSA, 2004, p. 192).

Essa atuação intencional de educador no modo como o "não pode" foi anunciado faz-me lembrar duma entrevista que fiz com uma professora da educação infantil a quem perguntei sobre o seu modo de trabalho com as crianças e ela respondeu “(...) que no primeiro dia de aula, não sorria para a classe de alunos e depois ia se soltando" (RODRIGUES, 2008, p. 13) e isso seria somente possível quando tivesse certeza que estava controlando completamente toda a turma.

Esses mecanismos que instituem o controle, a estrutura e o funcionamento do "modelo de ensino" é que podemos analisar a dificuldade em compreender que os efeitos do "não pode", que educa como elemento de contenção para o direcionamento no ingresso no campo da cultura para aquele que não seja de intensidade inibitória. O "não pode" que permite o ingresso no campo da cultura seria aquele que pode abrir outras tantas possibilidades em diversas maneiras de fazer as coisas e que pode servir para se pensar o contrário das coisas no momento em que ele se faz pronunciado. Portanto, o "não pode" que permite pensar a vida é o que constitui a responsabilidade do adulto, que em tese compreende que sua transgressão tem como princípio ter que arcar com as consequências dos seus atos. A passagem de uma criança para a condição de adulto é a condição de principalmente elaborar a recusa, aceitar em parte ou sublimar as pulsões (FREUD, 1996a).

Penso que, muitas vezes, a tarefa de pai e de educador é como a de um sujeito que transmite um saber que não sabe. Algo semelhante sobre o saber de como se deveria surfar a questão de que "não há saber sobre o desejo" (LAJONQUIÈRE, 1992, p. 226). Quando você vai surfar numa onda no mar, não existe um programa ou modelo de como fazer o surfe. O que existe é uma relação no tempo e no espaço em que ocorrem os acontecimentos entre o sujeito com a prancha e a onda e, portanto, não existe um a priori. Nada se repete, apesar das ondas em que se surfa ser praticamente uma constante em repetição. Uma onda perdida nunca volta. Quem sabe melhor lidar com esse mar de ondas e, 
principalmente, como surfar o "isso não pode", adquire um saber de algo que não se tem saber - não seria isso a função do processo analítico? Sobre o "não pode" como elemento de processo inibitório do pensamento, são diversos os exemplos e o espaço escolar, como outras instituições, encontram-se plenamente constituído nessa prática e, portanto, não é por acaso que os saberes no interior da unidade escolar denominam-se disciplina.

\section{CENA 3 - O BRINCAR DESTITUÍDO DE SENTIDO OU QUANDO A ESCOLA VIRA O PARQUE DA DISNEY}

Após as férias do meio do ano de 2016, fui levar a minha filha na escola e encontro, no meio do pátio da escola, um enorme brinquedo, que se tratava de um escorregador gigante em forma de caracol. Chego em casa e falo para a minha esposa: "O pátio da escola da nossa filha está parecendo um salão de festa infantil". Aqui que se apresenta o verdadeiro paradoxo sobre a questão do brincar na escola, pois como podemos inserir o brincar como elemento que produza o processo formativo no campo da cultura ao invés de destituir essa função do espaço escolar?

Isso leva a pensar que não se trata de ir à escola para brincar. O que não quer dizer que o "trabalho escolar" não seja animado por algo da ordem do brincar sem por isso ser uma brincadeira.

Passado alguns meses depois tivemos um encontro de final de semana na escola e, por acaso, converso com a coordenadora pedagógica sobre o assunto do escorregador no meio do pátio numa tentativa de tentar compreender como brincar atravessa a questão do processo formativo dessa escola. A mesma, muito simpática, pergunta como as coisas vão. Respondo que as coisas vão bem e que sempre busco estar disponível para falar com a minha filha sobre as coisas da vida, que aproveito esses momentos para ler e escrever as coisas com ela, principalmente, nas férias escolares. Ela arregala os olhos como se fosse algo fora do comum e responde "Mas ela é apenas uma criança! Ela tem que brincar!". Respondo "Ela brinca todo o tempo e inclusive o resto do tempo do dia”. Fica aquele silêncio com certo malestar e ela me diz "Ah! Eu somente sei brincar. Para mim, tratando-se de criança tudo é brincadeira e eu viro uma criança!”. 
A nossa compreensão é que as crianças trabalham para fazer uma passagem para o mundo dos adultos. Pergunto: como e por que uma criança vai trabalhar para fazer a passagem para o mundo dos adultos numa escola que coloca no meio do pátio das "crianças grandes" um brinquedo que as posicionam como infantil sem fala e sem representação e, portanto, que o brincar é o contrário do trabalho do processo imaginativo?

Para a minha filha, não pronuncio uma única palavra sobre o escorregador que possa vir a desmerecer o espaço escolar. Apenas dou tempo ao tempo para que ela possa perceber, no meu modo de olhar, que isso produz em mim um tremendo desconforto, pois o mundo escolar do adulto é outra coisa que não reproduz em seu espaço escolar a Disneylândia.

Diria que essa inversão do brincar como conteúdo escolar ocorre uma vez que deixamos de ter o lugar do brincar sem significado pelo olhar da criança e esse passa a entrar na escola como a qualidade do brincar que possa ser significado com o olhar do adulto, que vê nesses equipamentos a realização do divertimento como sendo o "verdadeiro aprender brincando". Não seria isso a destituição do significado do brincar para a criança na passagem para o mundo adulto?

\section{CONSIDERAÇÕES FINAIS - O impossível brincar na escola e a transmissão do saber}

Recentemente, li uma notícia sobre um pai que matou o próprio filho e depois se matou (BORGES, 2016). Por morar num país muito bárbaro, que se pode perceber que são poucos os automóveis que param para um pedestre atravessar a faixa de segurança e com alto índice de violência, isso se apresenta como mais uma tragédia entre tantas que se anunciam em diversos jornais e telejornais. Entretanto, o motivo do crime, como tantos outros, é também algo completamente sem sentido, pois o filho era a favor das ocupações dos prédios públicos como maneira de protesto político. Segundo consta na notícia, ambos divergiam nesse assunto e tinham diversas discussões. No dia 16 de novembro de 2016, após mais uma discussão, o pai saiu de carro na caça do filho para atirar nele e depois se matar ao 
lado dele (BORGES, 2016). Tirando o elemento de tragédia do fato, isso deixa transparecer algo parecido a uma brincadeira infantil de pega-pega ou polícia e ladrão, mas com a perda do simbólico e na versão no real que se realiza no ato de efetivamente matar o outro.

Compreendemos que o processo civilizatório seria a condição na contenção ou redirecionamento do desejo em oposição ao ato e, portanto, evitar matar-nos uns aos outros, mas tudo indica que esse freio psíquico não está funcionando muito bem e algo vai muito mal em nosso tecido social e o que deixa transparecer seria

O elemento de verdade por trás disso tudo, elemento que as pessoas estão tão dispostas a repudiar, é que os homens não são criaturas gentis que desejam ser amadas e que, no máximo, podem defender-se quando atacadas; pelo contrário, são criaturas entre cujos dotes instintivos deve-se levar em conta uma poderosa quota de agressividade. Em resultado disso, o seu próximo é, para eles, não apenas um ajudante potencial ou objeto sexual, mas também alguém que os tenta satisfazer sobre ele a sua agressividade, a explorar sua capacidade de trabalho sem compensação, utilizá-lo sexualmente sem o seu consentimento, apoderar-se de suas posses, humilhá-lo, causar-lhe sofrimento, torturá-lo e matá-lo - Homo homini lúpus (FREUD, 1990a, p. 116).

Essa perda de vínculo traduz-se também no interior das instituições de ensino, em que cabe ao professor mediar os conflitos em detrimento de transmitir os elementos da cultura. No interior da tragédia no campo da cultura, o professor Leandro de Lajonquière (2009), ao analisar a ideia "Como a escola pode virar uma pizzaria" (LAJONQUIÈRE, 2009, p. 81), estabelece o argumento pautado na noção da autoridade, pois o que se encontra em questão é como o sujeito posiciona-se perante a Lei que interdita a satisfação do outro na constituição do processo civilizatório. Nesse caso, no "como a escola pode virar um parque de diversão" também entra em discussão a mesma questão da autoridade e, portanto, trata-se de saber lidar e compreender

(...) como um simples gesto evita que na escola nem tudo acabe em pizza. Pernoitando num vilarejo da região da Bretagne na França, assistimos o telejornal do dia. A notícia: O comissário da pequena cidade decide intervir para conter a "indisciplina escolar" que, no caso, reduzia-se ao fato de uma criança ter contestado verbalmente uma professora sem muita politesse. O comissário chamou a criança e seu pai e depois de um sermão sobre "boa educação" fez que ambos assinassem uma advertência escrita. (...) Sua intervenção adultiza a criança, no lugar de infantilizá-la, como de fato se faz quando da utilização da etiqueta "imaturidade psicológica". Por outro, instaura entre a 
criança e a professora uma dimensão terceira que corta o tête-à-tête e, dessa forma, recoloca a escola no lugar de representante do espírito das leis da cidade (LAJONQUIÈRE, 2009, p. 89-90).

Essa falta de inserção nos "espíritos das leis da cidade" ou o estado de regressão no processo civilizatório permite pensar algo incomum sobre o brincar, como fez Freud (1976) em seu trabalho de 1920, intitulado "Além do princípio de prazer" em que analisa algo mais, que se encontra presente no jogo ao observar

O menino tinha um carretel de madeira com um pedaço de cordão amarrado em volta dele. Nunca lhe ocorrera puxá-lo pelo chão atrás de si, por exemplo, e brincar com o carretel como se fosse um carro. O que ele fazia, era segurar o carretel pelo cordão e com muita perícia arremessá-lo por sobre a borda de sua caminha encortinada, de maneira que aquele desaparecia por entre as cortinas, ao mesmo tempo que o menino proferia seu expressivo 'o-o-o-ó”' (FREUD, 1976, p. 26).

Esse modo de brincar do menino Freud (1976) estabelece o pressuposto metapsicológico de que nesse ato de repetição encontra-se presente a possibilidade de elaborar algo que ainda não se compreende em termos de descarga da pulsão e, portanto, permite-se pensar a interpretação do brincar para além do comum que seria.

No caso da brincadeira, parece que percebemos que as crianças repetem experiências desagradáveis pela razão adicional de poderem dominar uma impressão poderosa muito mais completamente de modo ativo do que poderiam fazê-lo simplesmente experimentando-a de modo passivo. Cada nova repetição parece fortalecer a supremacia que buscam (FREUD, 1976, p. 52).

Desse modo, baseado nas cenas (01, 02 e 03 ) descritas anteriormente, permitimo-nos pegar uma carona nessa ideia de Freud sobre a tentativa de compreender que, nessas cenas, pode estar ocorrendo a tentativa de dominar algo que se "repete nas experiências desagradáveis". O processo formativo seria a condição em se tratando do brincar que “(...) nem tudo acabe em pizza” (LAJONQUIÈRE, 2009, p. 89), principalmente, possa-se compreender o brincar para além de simples diversão.

Podemos compreender que a precarização do aparelho escolar, em que o brincar pedagógico destitui-se de seu sentido lúdico e incorpora o conteúdo escolar é algo no campo da repetição, perde-se a condição elaborativa, pois o sujeito não 
repete por uma compulsão de si mesmo e sim por uma demanda alheia do outro. Assim, o processo de precarização do brincar no interior da unidade escolar não se trata apenas do apagamento da instauração da Lei, pois seria também, simultaneamente, a destituição da própria rotina escolar como elemento estruturante que se pauta na constituição do "faz de conta" em ser adulto e que nessa passagem o brincar poderia ser uma coisa séria na tentativa de elaborar o pensamento crítico. Portanto, retoma-se a ideia "Como a escola pode virar uma pizzaria" (LAJONQUIÈRE, 2009, p. 81) como algo que opera na unidade entre o apagamento da Lei estruturante do sujeito perante o desejo e a redução do pensamento crítico na instauração da banalidade do infantil, que não fala e escorrega para fora do processo civilizatório.

Conclui-se que isso que não se quer pensar do brincar no campo educacional seriam as novas configurações da singularidade do sujeito e que, no plural do social, reduz-se à severidade da formação profissional e, paradoxalmente, em sujeitos alheios à cultura e destituídos de pensamento crítico. Desse modo, a dificuldade de encontro entre os sujeitos e a ideia da unidade escolar como uma pizzaria ou salão de festa é algo que, de um lado, pode funcionar mecanicamente sem a autoridade e que tudo em seu interior "acabe em pizza ou em diversão", por outro lado, a terrível constatação de que o espaço escolar seja de fato uma pizzaria ou salão de festa, como lugar do nada e da distração pautada na futilidade, sem o acontecimento do encontro do sujeito no campo da cultura. Portanto, por um lado, interpreta-se o "escorregar" no meio do pátio escolar como isso que não se sabe dizer em palavras e que se faz em ato, pois:

(...) as crianças e jovens escorregam com facilidade do lugar do estrangeiro/familiar para os lugares, seja do selvagem ou do extraterrestre. Como eu afirmo no livro, essas duas figuras são a-educativas por definição, ou seja, quando o adulto que se endereça à criança é habitado no fantasma por uma ou outra figura, a palavra educativa é abortada e, portanto, as condições de uma educação se desmancham no ar, confrontando a criança de forma brutal contra o real do tempo. Daí as crianças nos jogarem na cara o retorno no real do que nada queremos saber para o nosso desconforto, mas também para o sofrimento delas. (LAJONQUIÈRE, 2013, p. 111 - grifo nosso) 
Por outro lado, como interpretar isso, o escorregador sem sentido no meio do pátio ou a terra que a criança jogou no pé da moça e que tanto a incomodou? Apenas diria que quando não se pode jogar na cara, joga-se no pé o retorno do real ou quando não se significa o escorregador no meio do pátio da escola o mesmo institui a barbárie no campo escolar. Aqui se encontra o verdadeiro centro da nossa questão que seria retornar o brincar no campo escolar como elemento próprio da cultura e que não seja algo fútil e sem significado e, portanto, um problema para ser enfrentado por todos os intelectuais que possam pensar a prática educativa que seja divertida e alegre no ato de aprender as coisas no campo da cultura.

\section{REFERÊNCIAS}

BAUMAN, Z. A cultura no mundo líquido moderno. Trad. Carlos Alberto Medeiros. Rio de Janeiro: Zahar, 2013.

BORGES, Fernando. Filho morto pelo pai foi proibido de ocupar escola, diz família à polícia. Disponível em <http://g1.globo.com/goias/noticia/2016/11/filho-morto-pelo-paifoi-proibido-de-ocupar-escola-diz-familia-policia.html> Acesso em: 17 nov. 2016.

FREUD, Sigmund. Além do principio de prazer (1920). In: FREUD, Sigmund. Obras Completas. v. XVIII. Trad. Jayme Salomão. Rio de Janeiro: Imago, 1976.

FREUD, Sigmund. Cinco lições de Psicanálise (1910 [1909]). In: FREUD, Sigmund. Obras Completas. v. XI. Trad. Jayme Salomão. Rio de Janeiro: Imago, 1996a.

FREUD, Sigmund. O Mal-Estar na Civilização (1930 [1929]). In: FREUD, Sigmund. Obras Completas. v. XXI. Trad. Jayme Salomão. Rio de Janeiro: Imago, $1990 a$.

FREUD, Sigmund. Novas conferências introdutórias sobre a Psicanálise (1933 [1932]). Conferências XXXIV Explicações, aplicações e orientações. In: FREUD, Sigmund. Obras Completas. v. XXII. Trad. Jayme Salomão. Rio de Janeiro: Imago, 1990b.

FREUD, Sigmund. Lo siniestro. 1919. In: FREUD, Sigmund. Obras Completas Sigmund Freud. v. III. Trad. Luis López-Ballesteros y de Torres. Madrid: Biblioteca Nueva, 1996b.

IBGE - Instituto Brasileiro de Geografia e Estatística. Disponível em $<$ http://biblioteca.ibge.gov.br/index.php/bibliotecaatalogo ?view=detalhes\&id=443232>. Acesso em: 23 fev. 2017. 
LAJONQUIÈRE, Leandro. De Piaget a Freud: a (psico)pedagogia entre o conhecimento e o saber. 3 ed. Petrópolis, RJ: Vozes, 1992.

LAJONQUIÈRE, Leandro. A psicologização do cotidiano escolar desafia a interlocução necessária entre psicanálise e educação. Revista de Psicanálise, Ano 2, V. 1, N. 3, jul/dez, 2013.

LARROSA, Jorge. Pedagogia Profana: danças, piruetas e mascaradas. Trad. Alfredo Veiga-Neto. Belo Horizonte: Autêntica, 2004.

REDAÇÃO. Rolling Stones. Folha de S. Paulo, São Paulo, o3 de mar. 2016. Disponível em: <http://rollingstone.uol.com.br/noticia/parece-que-pessoas-emsao-paulo-assistem-ao-show-pelo-celular-diz-mick-jagger/>. Acesso em: 16 mar. 2017.

REIS, Magali dos \& RODRIGUES, Rogério. Dossiê - Ludicidade, Conhecimento e Corpo. In: Revista Em Aberto, Brasília: INEP,Vol. 31, No 102, maio/ago/2018.

RODRIGUES, Rogério. Educação e Psicanálise - As dinâmicas das práticas educativas e os mitos sobre as causas das dificuldades escolares: os problemas de aprendizagem. Projeto de Pesquisa Fapemig Universal. Itajubá: Fapemig. 2008.

Sobre o autor

Rogério Rodrigues. Graduação em Educação Física pela Universidade Estadual Paulista Júlio de Mesquita Filho - UNESP. Mestrado e doutorado em Educação pela Faculdade de Educação da UNICAMP (2004). Pós-doutorado na Faculdade de Educação da Universidade de São Paulo, FE (USP). Docente Associado Nível IV da Universidade Federal de Itajubá - UNIFEI. Professor e Pesquisador do Programa de Pós-graduação em Desenvolvimento, Tecnologias e Sociedade (UNIFEI). E-mail: rrunifei@hotmail.com rrunifei@hotmail.com

Agradecimento à Universidade Federal de Itajubá (UNIFEI) e ao mestrado em Desenvolvimento, Tecnologias e Sociedade (UNIFEI). 